\title{
Influence du séchage sur la digestibilité des feuilles de deux légumineuses arbustives
}

\author{
S Touré-Fall 1, D Friot 2, B Michalet-Doreau 3, D Richard 2 \\ IISRA-LNERV, B.P. 2057 - Dakar, sénégal; ²CIRAD-EMVT, B.P. 5035 - 34032 Montpellier Cédex, France \\ 3INRA de Theix, 63122 St Genes-Champanelle, France
}

Les fourrages ligneux représentent une part importante du régime des ruminants domestiques en zone sahélienne. Leur valeur nutritive est cependant très variable. Elle dépend de l'espèce, des organes consommés, du stade phénologique, de la saison, du mode de séchage, ... (Fall, 1993, Thèse Doct ENSAM, $139 \mathrm{p}$ ).

Pour définir un mode de conservation optimal, l'influence du séchage sur la digestibilité de la matière sèche (dMS) des feuilles de deux légumineuses arbustives fourragères (Albizzia lebbeck et Pithecellobium dulce) a été étudiée.

Les feuilles des deux ligneux ont été récoltées au stade feuillaison dans la zone des Niayes au Sénégal. Elles ont été distribués aux animaux à l'état frais ou après séchage au soleil. Ces feuilles ont été associées à une ration de base composée de paille de riz $(85$ p.100) et tourteau d'arachide (15 p.100) pour obtenir une ration totale dont la teneur en matières azotées totales (MAT p.100 MS) ne soit pas inférieure à 10. Les rations ont été distribuées en quantité limitée ; les feuilles ont représenté 50 et 57 p. 100 de la MS totale ingérée respectivement pour $A$. lebbeck et $P$. dulce.

Le digestibilité des rations a été mesurée au LNERV sur six ovins de race Peul-peul d'un poids moyen de $30 \mathrm{~kg}$ et âgés de 18 mois. Chaque essai durait 21 jours dont 15 jours d'adaptation au régime et six jours de mesure. Deux essais de digestibilité ont été réalisés par échantillon.

La digestibilité du ligneux a été calculée par différence. La signification de l'influence du séchage sur la digestibilité des ligneux a été appréciée par analyse de variance.

Les dMS moyennes des rations totales ont été de 48,6 et 52,0 p.100 respectivement pour $A$. lebbeck et $P$. dulce, celles des feuilles de 42,9 et 53,2 p. 100 .

Le séchage a entraîné une diminution significative $(P<0.05)$ de 3,1 points de la dMS de la ration contenant $P$. dulce alors qu'il a peu modifié celle contenant $A$. lebbeck. Cette diminution est encore plus marquée pour les feuilles seules : $-6,3$ points pour $P$. dulce, $-2,7$ pour $A$. lebbeck (voir table).

Des résultats contradictoires sont également rapportés dans la bibliographie en ce qui concerne l'influence du séchage sur la valeur nutritive des fourrages. Pour certains auteurs, le séchage provoque une chute de la digestibilité des fourrages (Parra et al, 1989, Trop Anim Prod, 9, 169-199; Abdalla et al, 1987, J Anim Sci, 66, 2646-2649), alors que d'autres n'ont observé que des modifications mineures (Beever et Thomson, 1981, Grass For Sci, 36, 211-219). Ces différences peuvent être induites par le type de fourrage mais aussi par les conditions du traitement caractérisées par sa durée et la température appliquée. Dans le cas des ligneux, l'effet du séchage pourrait être compliqué par la présence de composés secondaires.

Des études complémentaires ciblant un plus grand nombre d'espèces ligneuses auraient un intérêt certain pour préciser les modifications chimiques provoquées par le séchage concernant en particulier les substances potentiellement toxiques dont certaines semblent pouvoir être transformées au cours du séchage (Lowry, 1989, in: C Devendra, ed, Proc Workshop Denpasar).

\section{Espèce ligneuse}

Conditionnement

MS Initiale (\%)

MAT (\% MS)

Taux de ligneux dans

la ration (\% MS)

dMS ration (\%)

dMS ligneux ( $\%$ MS)

Signification de la différence

\section{Pithecellobium dulce}

Frais Séché

41,8

17,1

57,5

53,6

56,4

$P<0,05$

\section{Albizzia lebbeck}

\begin{tabular}{ll} 
Frais & Séché \\
40,6 & 93,4 \\
14,6 & 14,6 \\
50,5 & 50,0 \\
48,0 & 49,2 \\
41,6 & 44,3 \\
\multicolumn{2}{c}{ Non significatif }
\end{tabular}

